\title{
Treatment of benign prostatic hyperplasia with finasteride: Evidence from a meta-analysis
}

\author{
Tao Jiang ${ }^{1 *}$, Ying Zhang ${ }^{2}$, Zhilin $\mathrm{Hu}^{1}$, Bin Jiang ${ }^{1}, \mathrm{Xu} \mathrm{Hou}{ }^{1}$ \\ ${ }^{1}$ Department of Urology, ${ }^{2}$ Department of ENT, Dalian Friendship Hospital, Zhongshan District, Dalian 116001, Liaoning \\ Province, China \\ *For correspondence: Email: taojiangv@sina.com; Tel: +864118393526; Fax: +864118393526

\begin{abstract}
Purpose: To clarify the usefulness and safety of finasteride in the treatment of patients with benign prostatic hyperplasia (BPH) compared to placebo group or controls.

Methods: In a meta-analysis, PubMed and Web of Science were searched to include relevant studies. The results were combined with a random effect model. Publication bias was evaluated using Egger regression asymmetry test.

Results: Fourteen publications involving 17,364 patients were included in the study. Pooled results indicated that International Prostate Symptom Score (IPSS) in the finasteride group was lower [weighted mean difference $(W M D)=-0.77,95 \% \mathrm{Cl}=-0.97$ to -0.57 ] compared to the placebo group. The usefulness of finasteride was higher in total prostate volume (TPV) [WMD $=0.13,95 \% \mathrm{Cl}=0.00$ to 0.26 ] but lower in serum DHT [WMD =-1.18, $95 \% \mathrm{Cl}=-1.51$ to -0.86$]$ when compared to the placebo group. Drug-related adverse event was higher in the finasteride treatment group when compared to placebo group [summary $R R=1.95,95 \% \mathrm{Cl}=1.31-2.90$ ].

Conclusion: Finasteride could improve the symptom score (IPSS and TPV) and reduce serum DHT. However, the potential adverse events, especially the drug-related adverse events in Finasteride treatment should be attention.
\end{abstract}

Keywords: Benign prostatic hyperplasia, Finasteride, Meta-analysis

\begin{abstract}
This is an Open Access article that uses a funding model which does not charge readers or their institutions for access and distributed under the terms of the Creative Commons Attribution License (http://creativecommons.org/licenses/by/4.0) and the Budapest Open Access Initiative (http://www.budapestopenaccessinitiative.org/read), which permit unrestricted use, distribution, and reproduction in any medium, provided the original work is properly credited.

Tropical Journal of Pharmaceutical Research is indexed by Science Citation Index (SciSearch), Scopus, International Pharmaceutical Abstract, Chemical Abstracts, Embase, Index Copernicus, EBSCO, African Index Medicus, JournalSeek, Journal Citation Reports/Science Edition, Directory of Open Access Journals (DOAJ), African Journal Online, Bioline International, Open-J-Gate and Pharmacy Abstracts
\end{abstract}

\section{INTRODUCTION}

In aging men, it is a common disease with benign prostatic hyperplasia $(\mathrm{BPH})$. Urinary tract obstruction and even complete urinary retention often accompanied by prostate enlargement [1]. $\mathrm{BPH}$ can lead to bladder outlet obstruction (BOO), incomplete bladder emptying, poor stream and hesitancy. Therefore, it could affect a person's quality of life [2,3]. In some more advanced situations, the risk with enlarged prostates $(>30 \mathrm{~mL}$ ) could increase three fold among men with acute urinary retention (AUR) [4].

Finasteride belongs to the competitive inhibitor of 5a-reductase [5]. Application of this drug in a short period of time resulted in a decrease in serum dihydrotestosterone concentrations, a reduction in the prostate volume, and an 
improvement in urinary flow rate [6,7]. While some studies [8-10] reported the effectiveness of finasteride in $\mathrm{BPH}$, others did not find it better than the placebo or control [11]. Thus, the aim of this meta-analysis was to compare the outcomes of the treatment of $\mathrm{BPH}$ using finasteride.

\section{METHODS}

\section{Search criteria and inclusion criteria}

PubMed and Web of Knowledge databases were reached for records as at May 2015. The search utilized the terms 'benign prostatic hypertrophy', 'prostatic hyperplasia', or 'BPH' in combination with 'finasteride' or '5ar inhibitor'. List of references from all full research and review articles retrieved were also used to identify other relevant articles. All the articles and abstracts were reviewed.

Two investigators independently searched and reviewed articles for eligibility using the following inclusion criteria:: (1) written in English; (2) used randomized controlled trials (RCTs) design; (3) exposure of interest was the treatment using finasteride; (4) disease of interest was $\mathrm{BPH}$, and (5) mean and standard deviation (SD) for International Prostate Symptom Score (IPSS), total prostate volume (TPV) $\left(\mathrm{cm}^{3}\right)$, peak urinary flow $\left(Q_{\max }\right)(\mathrm{ml} / \mathrm{s})$, serum testosterone $(\mathrm{pg} / \mathrm{ml})$ or dihydrotestosterone (DHT) $(\mathrm{pg} / \mathrm{ml}$ ) (or data to calculate them were provided) and the number of adverse events $(A E)$ and withdrawal due to $A E$ were provided.

\section{Data extraction}

The following data independently extracted by two authors from studies included: first author's last name, publication years, sample size, age, the methods of treatment, treatment duration, the mean and SD for continuous variables, the numbers of any $A E$, withdrawal due to $A E$, drugrelated $\mathrm{AE}$, and serious $\mathrm{AE}$ for dichotomous variables.

\section{Statistical analysis}

Dichotomous data were presented as odds ratios (OR) and $95 \%$ confidence interval $(95 \% \mathrm{Cl})$, and continuous parameters were shown as weighted mean difference (WMD) and 95\% Cl. Pooled treatment effect was determined with a randomeffects model, which considers between-study variation [12]. Heterogeneity was assessed by using $P^{2}$ statistic [13]. Egger's test was used to assess the publication bias [14]. A sensitivity analysis by exclusion of one study at the time was performed to assess the stability of results and potential sources of heterogeneity [15]. Meta-analysis was performed on STATA version 10.0. The level of significance was defined as $p$ value $\leq 0.05$.

\section{RESULTS}

\section{Characteristics of included studies}

From the search, 487 publications from PubMed and 582 publications from Web of Knowledge were retrieved. A total of 1031 studies were excluded on review of each of the abstract or title. As shown in Figure 1, another 24 publications were further excluded. Thus, 14 publications [8-11, 16-25] (Table 1) covering 17,364 patients were utilized for this report. When a clinical trial reported different outcomes, we then regarded them as a separate study. There were 11 articles that assessed the relationship between finasteride and placebo for $\mathrm{BPH}$ risk, 2 publications assessed the association between finasteride and dutasteride for BPH risk, and 2 studies for finasteride and tamsulosin.

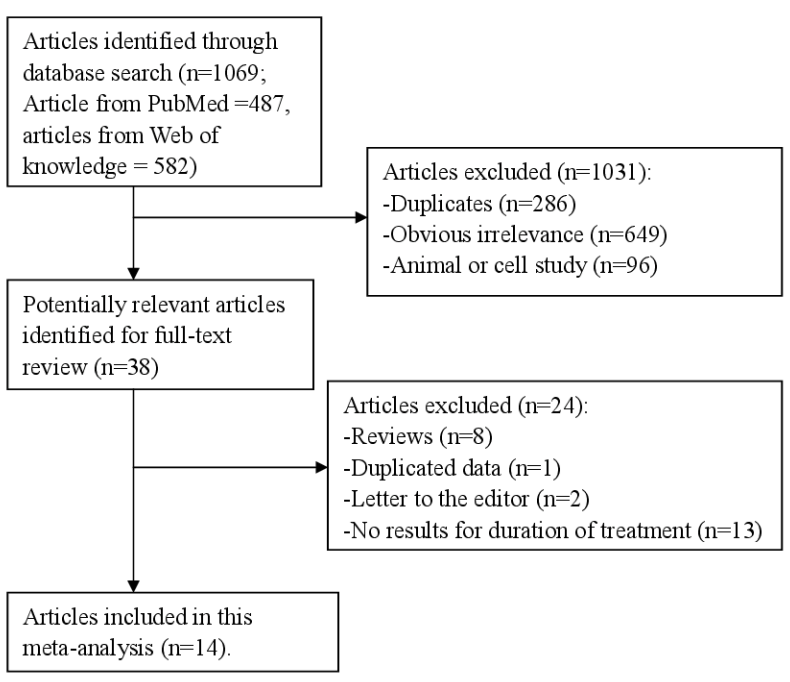

Figure 1: Study flow chart

\section{Efficacy of finasteride interventions}

There was only one study that reported the association for IPSS, and a significantly greater reduction in finasteride group than placebo group $(\mathrm{WMD}=-0.77,95 \% \mathrm{Cl}=-0.97$ to -0.57$)$. The relation between finasteride group and placebo for BPH treatment was not significant in $Q_{\max }$ $(\mathrm{WMD}=-0.01,95 \% \mathrm{Cl}=-0.14$ to 0.11 ) (Figure 2). Four studies reported the association for finasteride treatment and TPV, and the association was significant in the treatment of finasteride group than placebo group (WMD= $0.13,95 \% \mathrm{Cl}=0.00$ to 0.26 ) (Figure 3 ). The 


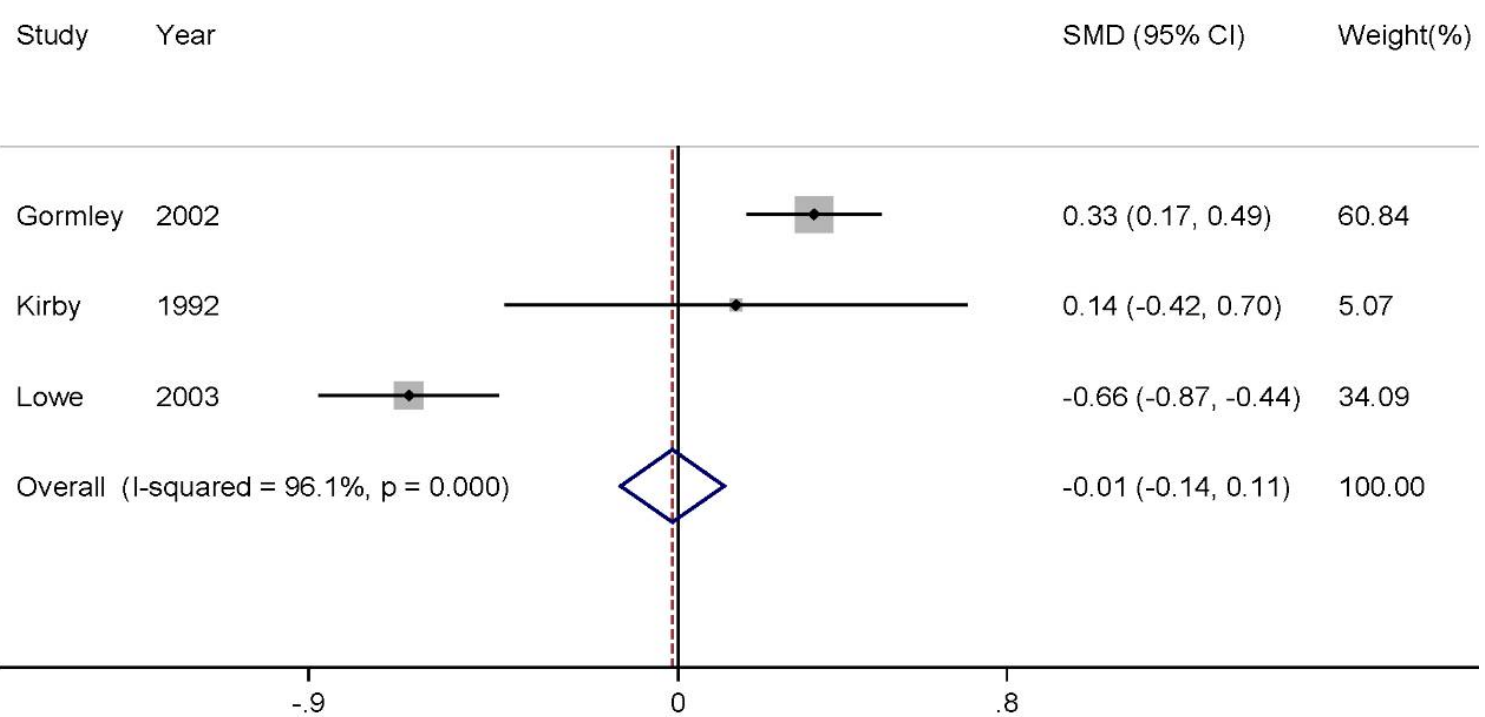

Figure 2: Forest plot and meta-analysis of the treatment for finasteride compared with placebo group with respect to $Q_{\max }$

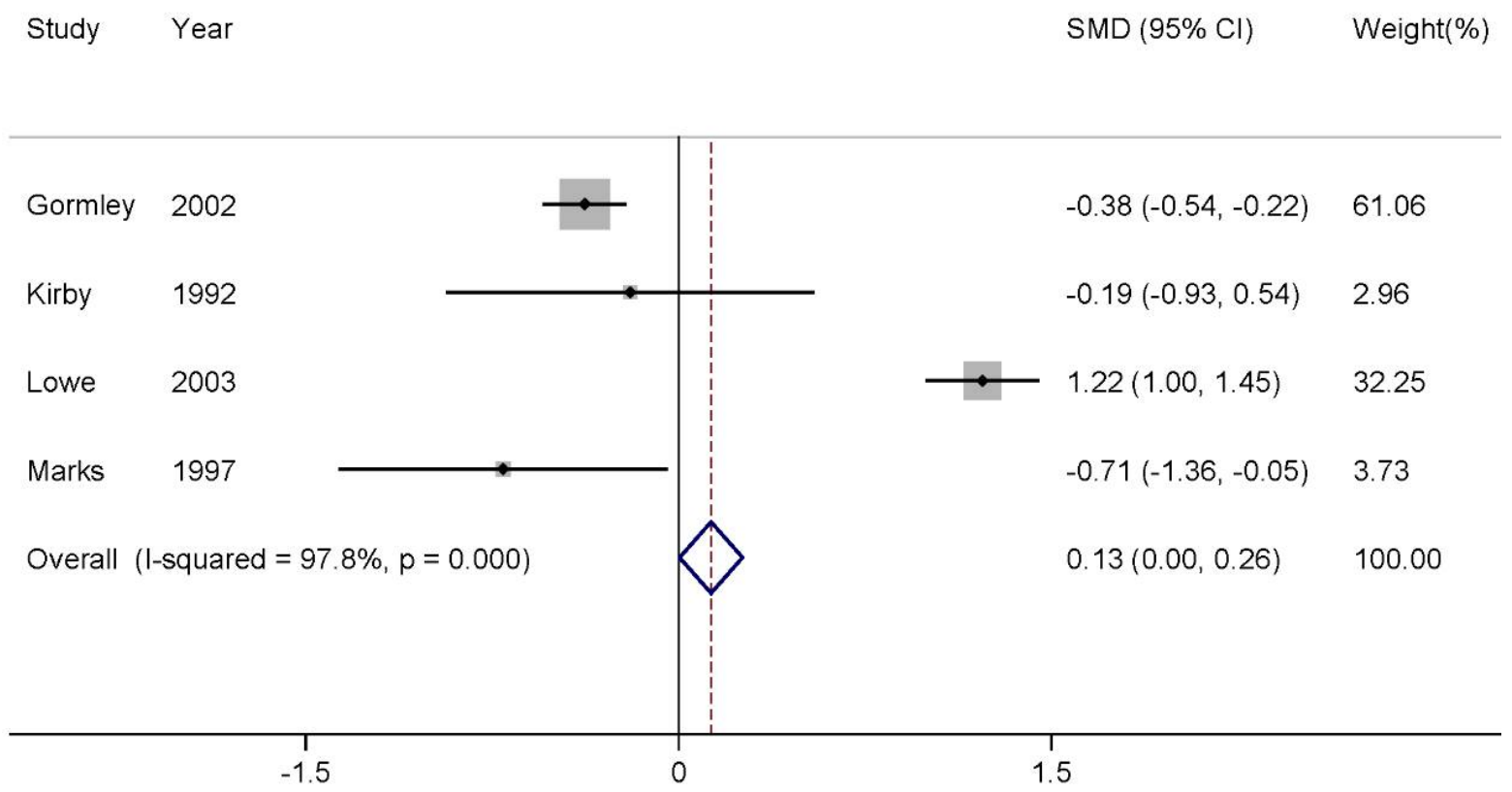

Figure 3: Forest plot and meta-analysis of the treatment for finasteride compared with placebo group with respect to TPV

treatment by finasteride showed a significant reduction association in serum $\mathrm{DHT}(\mathrm{WMD}=-$ $1.18,95 \% \mathrm{Cl}=-1.51$ to -0.86 ) (Figure 4 ) and increase but not significant in serum testosterone $(\mathrm{WMD}=0.19,95 \% \mathrm{Cl}=-0.12$ to 0.50$)$ (Figure 5$)$.

In addition, the treatment effects between finasteride group and tamsulosin group showed that no significant association was found in the analyses for IPSS and $Q_{\max }$. The treatment effects of finasteride were supported by a significant increase in serum DHT compared with dutasteride group $(\mathrm{WMD}=1.49,95 \% \mathrm{Cl}=1.07$ to 1.91).

\section{Safety of finasteride interventions}

There are 6 studies conducted to assess the association of finasteride with AE. Pooled data indicated that there was no significant association in $A E$ in treatment with finasteride than placebo $(R R=1.00,95 \% \mathrm{Cl}=0.94-1.07)$ (Figure 6). The association was not significant in withdrawal due to $A E$ for the treatment with finasteride than placebo $(R R=0.98,95 \% \mathrm{Cl}=$ $0.85-1.14)$. Pooled data indicated drug-related $\mathrm{AE}$ were higher in finasteride group than that in placebo group (RR=1.95, $95 \% \mathrm{Cl}=1.31-2.90)$ (Figure 7). No significant association was found in the serious $\mathrm{AE}(\mathrm{RR}=0.91,95 \% \mathrm{Cl}=0.80-1.03)$ 


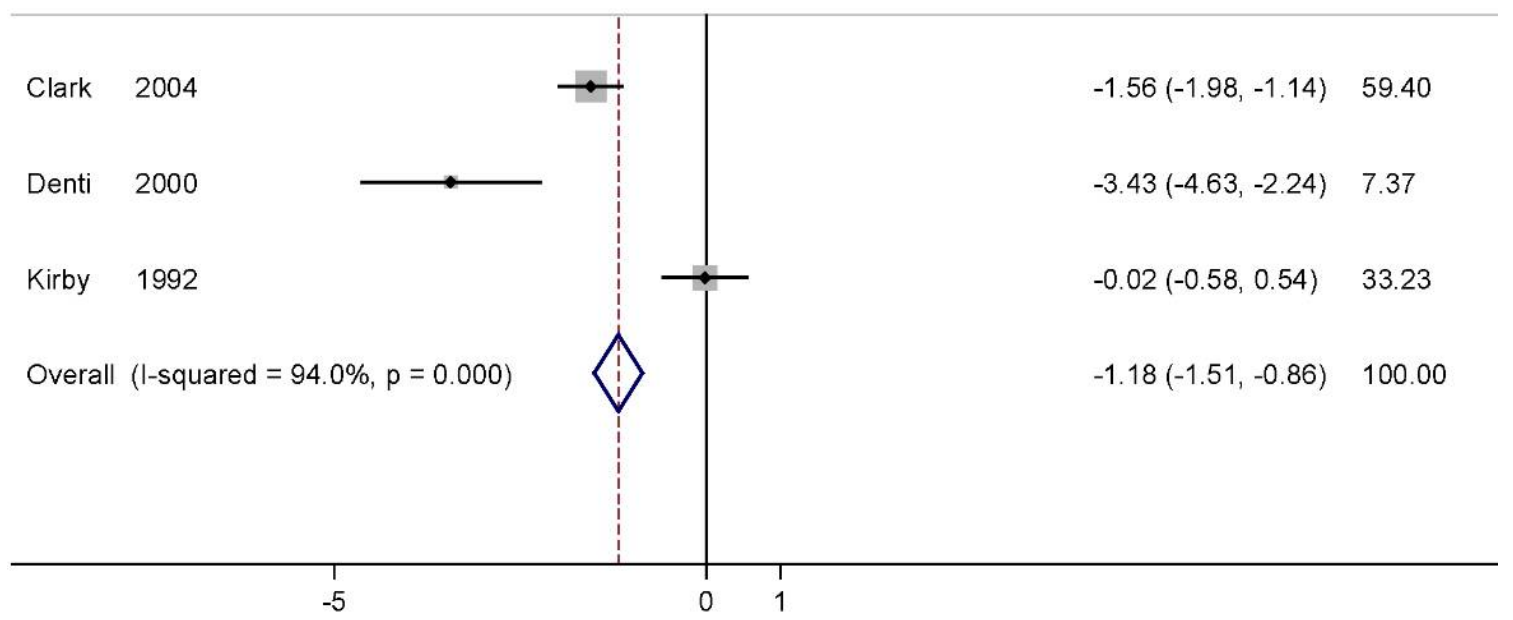

Figure 4: Forest plot and meta-analysis of the treatment for finasteride compared with placebo group with respect to serum DHT.

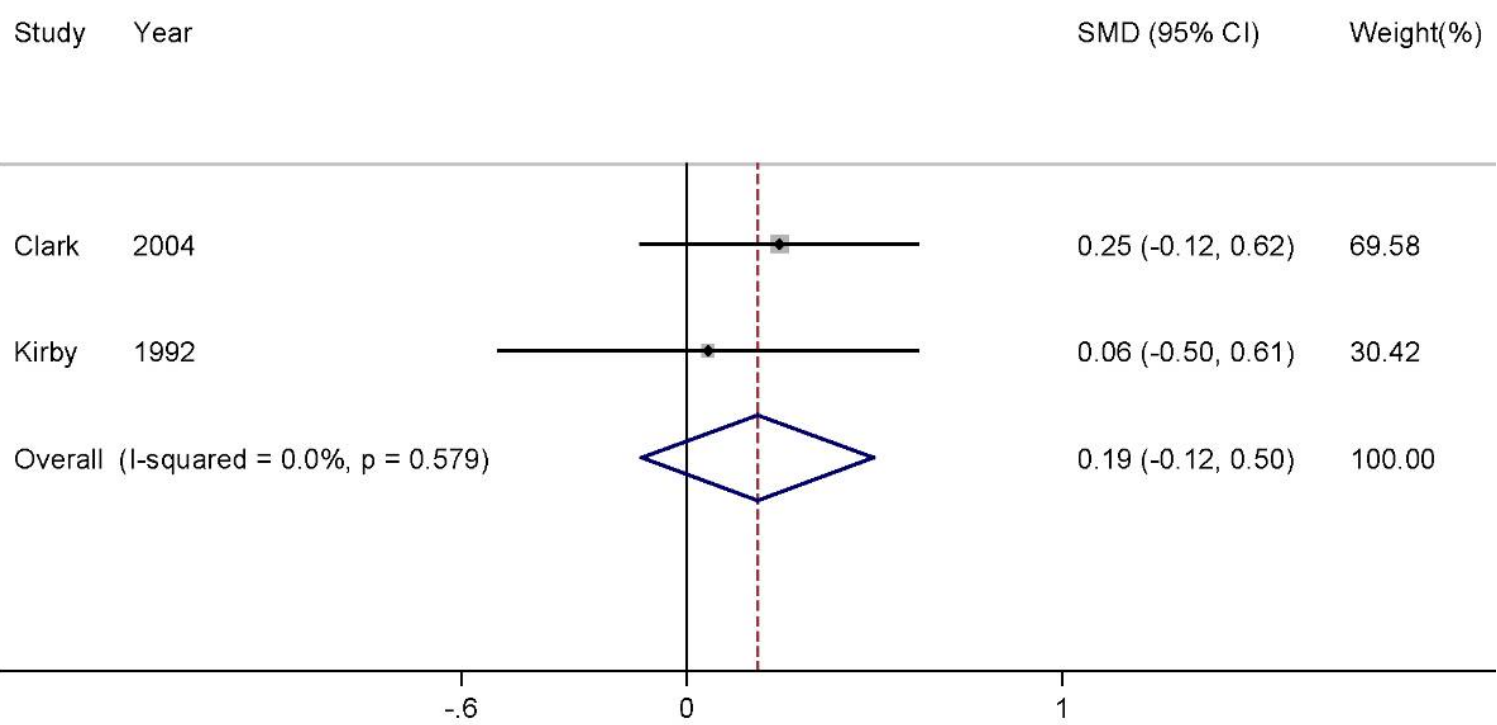

Figure 5: Forest plot and meta-analysis of the treatment for finasteride compared with placebo group with respect to serum testosterone

In addition, withdrawal from finasteride or tamsulosin was not associated with ADE, drugrelated adverse events. Similarly, ADE and withdrawal due to adverse events were not significantly associated with the treatment of finasteride compared with dutasteride group.

\section{Sensitivity analysis and publication bias}

A sensitivity analysis of the relationship between finasteride group and placebo group was conducted accordingly. However, no apparent effect was found on overall merged results. The potential publication bias assessed by Egger's test $(P=0.176)$ showed no significant publication bias between finasteride group and placebo group for the treatment of BPH was found.

\section{DISCUSSION}

Findings from this study demonstrated that finasteride could improve the symptom score of IPSS and TPV. The treatment effect of finasteride had a reduction in serum DHT compared with placebo group. However, drugrelated $A E$ reported higher in the finasteride group than in the placebo group. No significant associations were found in other three adverse events group. We also found a greater increased in serum DHT for the efficacy of finasteride than that in dutasteride group. 


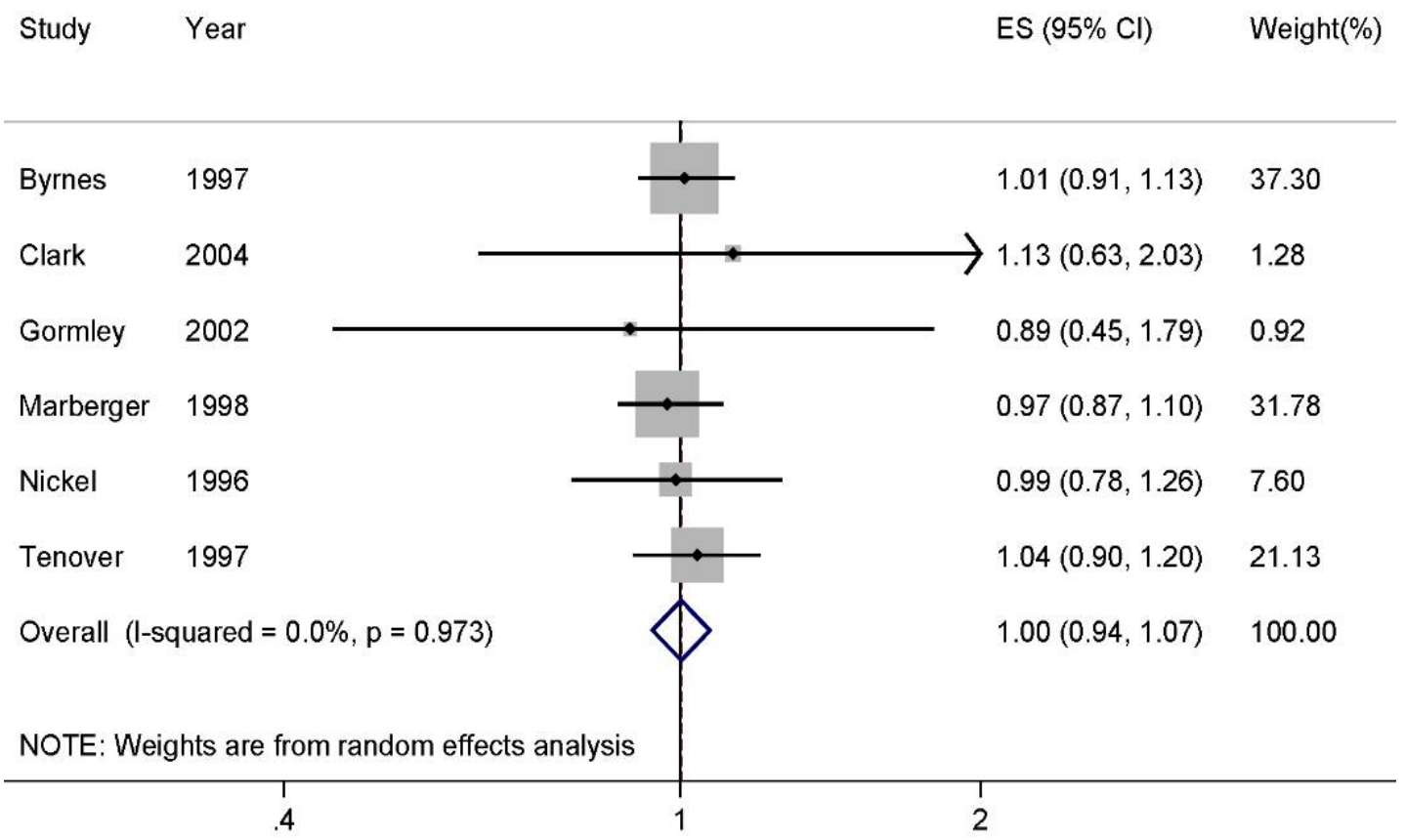

Figure 6: The forest plot of BPH symptoms measured by AE about finasteride compared with placebo group.

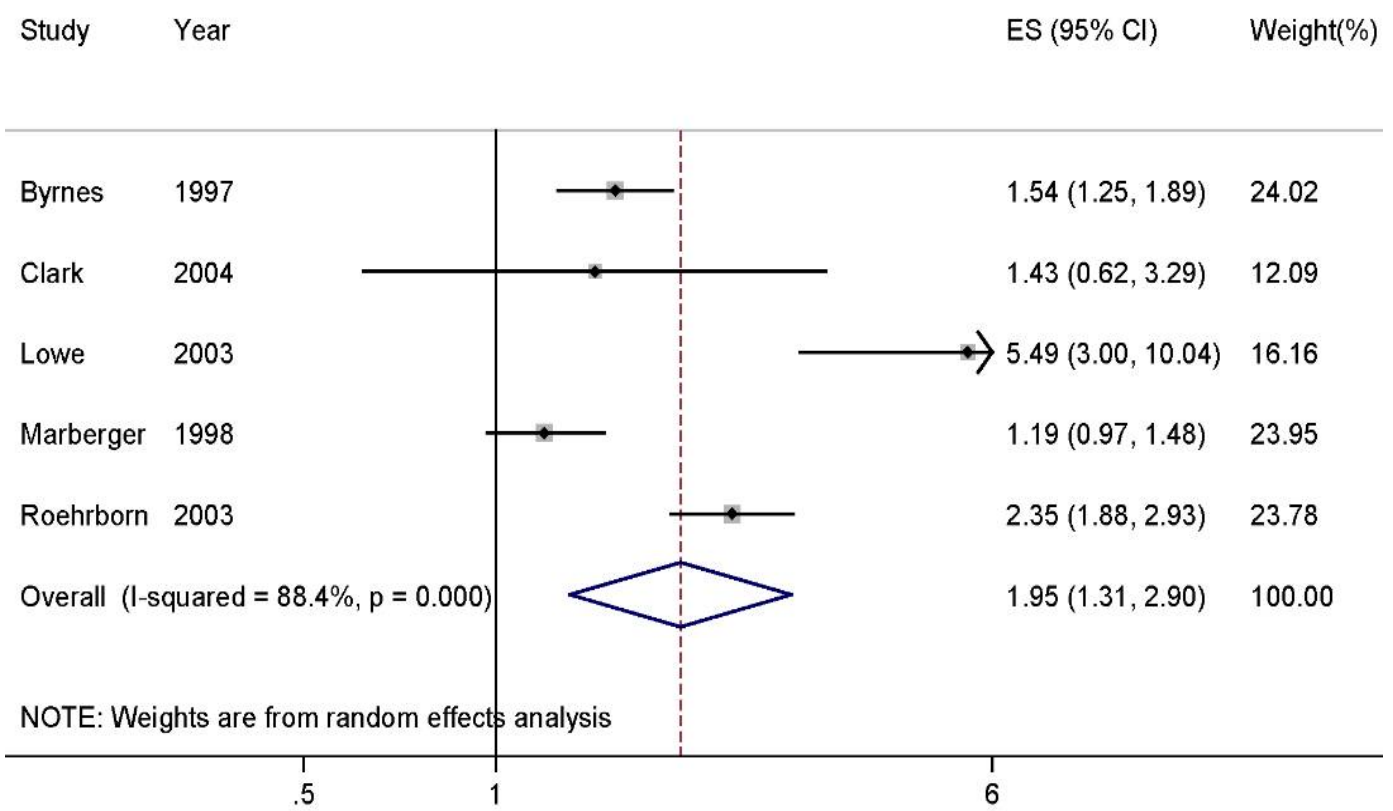

Figure 7: The forest plot of BPH symptoms measured by drug-related adverse events about finasteride compared with placebo group

Several mechanisms have been proposed to explain the possible role of finasteride in the treatment of $\mathrm{BPH}$. Finasteride belongs to 5 -alpha reductase inhibitor (5-ARI), which is known to inhibit BPH-related disease progression by blocking 5-alpha reductase (5AR), which converts testosterone to DHT, a hormone responsible for prostate growth. Finasteride is a selective inhibitor of type II 5AR that could reduce the circulating $\mathrm{DHT}$ levels by about $70 \%$ [26]. The results in our study are similar to the previous meta-analysis of dutasteride treatment in urinary symptoms (IPSS and $Q_{\max }$ ), TPV, and potential $A E$ [27]. Like finasteride, dutasteride is a 5-ARI and may have the same effect as finasteride in the treatment of $\mathrm{BPH}$.

The major strength in this meta-analysis is the absence of any significant publication bias as demonstrated with the Egger's test. However, the number of articles analysed are limited by our inclusion criteria. In addition, different doses of the drugs (finasteride: once daily (OD): $5 \mathrm{mg}$, Dutasteride: OD $0.5 \mathrm{mg}$, Tamsulosin: OD $0.4 \mathrm{mg}$ 
or $0.2 \mathrm{mg}$ ) were used in the studies that may lead to between-study heterogeneity. However, a random effect model was used in this report, which assumes that the individual specific effects are uncorrelated with the independent variables. Furthermore, the lack of information on the distribution of clinical and methodological variables can lead to potential sources of heterogeneity or inconsistency in each of the more specific test groups.

\section{CONCLUSION}

This study suggests that finasteride improves symptom score (IPSS and TPV) and reduce serum DHT in patients with BPH. However, potential $A E$, especially drug-related $A E$ should be given special attention in finasteride treatment.

\section{DECLARATIONS}

\section{Conflict of Interest}

No conflict of interest associated with this work.

\section{Contribution of Authors}

The authors declare that this work was done by the authors named in this article and all liabilities pertaining to claims relating to the content of this article will be borne by them.

\section{REFERENCES}

1. Glynn RJ, Campion EW, Bouchard GR and Silbert JE. The development of benign prostatic hyperplasia among volunteers in the Normative Aging Study. Am J Epidemiol 1985; 121: 78-90.

2. Anderson JB, Roehrborn CG, Schalken JA and Emberton $M$. The progression of benign prostatic hyperplasia: examining the evidence and determining the risk. Eur Urol 2001; 39: 390-9.

3. Committee AUAPG. AUA guideline on management of benign prostatic hyperplasia (2003). Chapter 1: Diagnosis and treatment recommendations. J Urol 2003; 170: 530-47.

4. Jacobsen SJ, Jacobson DJ, Girman CJ, Roberts RO, Rhodes T, Guess HA and Lieber MM. Natural history of prostatism: risk factors for acute urinary retention. $J$ Urol 1997; 158: 481-7.

5. Rittmaster RS, Stoner E, Thompson DL, Nance $D$ and Lasseter KC. Effect of MK-906, a specific 5 alphareductase inhibitor, on serum androgens and androgen conjugates in normal men. J Androl 1989; 10: 259-62.

6. Gormley GJ, Stoner E, Rittmaster RS, Gregg $H$, Thompson DL, Lasseter KC, Vlasses PH and Stein EA. Effects of finasteride (MK-906), a 5 alpha-reductase inhibitor, on circulating androgens in male volunteers. $J$ Clin Endocrinol Metab 1990; 70: 1136-41.

7. Stoner E. The clinical effects of a 5 alpha-reductase inhibitor, finasteride, on benign prostatic hyperplasia. The Finasteride Study Group. J Urol 1992; 147: 1298302.

8. Clark RV, Hermann DJ, Cunningham GR, Wilson TH, Morrill $B B$ and Hobbs S. Marked suppression of dihydrotestosterone in men with benign prostatic hyperplasia by dutasteride, a dual 5alpha-reductase inhibitor. J Clin Endocrinol Metab 2004; 89: 2179-84.

9. Denti L, Pasolini G, Cortellini P, Sanfelici L, Benedetti R, Cecchetti A, Ferretti $S$, Bruschieri L, Ablondi $F$ and Valenti G. Changes in HDL-cholesterol and lipoprotein $L p(a)$ after 6-month treatment with finasteride in males affected by benign prostatic hyperplasia (BPH). Atherosclerosis 2000; 152: 159-66.

10. Lowe FC, McConnell JD, Hudson PB, Romas NA, Boake R, Lieber M, Elhilali M, Geller J, Imperto-McGinely J, Andriole GL, Bruskewitz RC, Walsh PC, Bartsch G, Nacey JN, Shah S, Pappas F, Ko A, Cook T, Stoner E, Waldstreicher $J$ and Finasteride Study G. Long-term 6year experience with finasteride in patients with benign prostatic hyperplasia. Urology 2003; 61: 791-6.

11. Kirby RS, Bryan J, Eardley I, Christmas TJ, Liu S, Holmes SA, Vale JA, Shanmuganathan $K$ and Webb JA. Finasteride in the treatment of benign prostatic hyperplasia. A urodynamic evaluation. Br J Urol 1992; 70: 65-72.

12. DerSimonian $R$ and Laird N. Meta-analysis in clinical trials. Control Clin Trials 1986; 7: 177-88.

13. Higgins JP, Thompson SG, Deeks JJ and Altman DG. Measuring inconsistency in meta-analyses. BMJ 2003; 327: 557-60.

14. Egger M, Davey Smith G, Schneider M and Minder C. Bias in meta-analysis detected by a simple, graphical test. BMJ 1997; 315: 629-34.

15. Tobias A. Assessing the in fluence of a single study in the meta-analysis estimate. Stata Tech Bull 1999; 47: 15-8.

16. Byrnes CA, Liss CL, Tenover JL, Lippert MC and Gillenwater JY. Combined analysis of two multicenter studies of finasteride $5 \mathrm{mg}$ in the treatment of symptomatic benign prostatic hyperplasia. Prostate Cancer Prostatic Dis 1997; 1: 26-31.

17. Gormley GJ, Stoner E, Bruskewitz RC, ImperatoMcGinley J, Walsh PC, McConnell JD, Andriole GL, Geller J, Bracken BR, Tenover JS, Vaughan ED, Pappas F, Taylor A, Binkowitz B, $\mathrm{Ng} J$ and Finasteride Study $G$. The effect of finasteride in men with benign prostatic hyperplasia. 1992. J Urol 2002; 167: 1102-7; discussion 8.

18. Lee E. Comparison of tamsulosin and finasteride for lower urinary tract symptoms associated with benign prostatic hyperplasia in Korean patients. $J$ Int Med Res 2002; 30: 584-90.

19. Marberger MJ. Long-term effects of finasteride in patients with benign prostatic hyperplasia: a double-blind, 
placebo-controlled, multicenter study. PROWESS Study Group. Urology 1998; 51: 677-86.

20. Marks LS, Partin AW, Gormley GJ, Dorey FJ, Shery ED, Garris JB, Subong EN, Stoner $E$ and deKernion JB. Prostate tissue composition and response to finasteride in men with symptomatic benign prostatic hyperplasia. $J$ Urol 1997; 157: 2171-8.

21. Nickel JC, Fradet $Y$, Boake RC, Pommerville PJ, Perreault JP, Afridi SK and Elhilali MM. Efficacy and safety of finasteride therapy for benign prostatic hyperplasia: results of a 2-year randomized controlled trial (the PROSPECT study). PROscar Safety Plus Efficacy Canadian Two year Study. CMAJ 1996; 155: 1251-9.

22. Nickel JC, Gilling P, Tammela TL, Morrill B, Wilson TH and Rittmaster RS. Comparison of dutasteride and finasteride for treating benign prostatic hyperplasia: the Enlarged Prostate International Comparator Study (EPICS). BJU Int 2011; 108: 388-94.

23. Rigatti $P$, Brausi M, Scarpa RM, Porru D, Schumacher $H$, Rizzi CA and Group MS. A comparison of the efficacy and tolerability of tamsulosin and finasteride in patients with lower urinary tract symptoms suggestive of benign prostatic hyperplasia. Prostate Cancer Prostatic Dis 2003; 6: 315-23.

24. Roehrborn CG, Lee M, Meehan A, Waldstreicher $J$ and Group PS. Effects of finasteride on serum testosterone and body mass index in men with benign prostatic hyperplasia. Urology 2003; 62: 894-9.

25. Tenover JL, Pagano GA, Morton AS, Liss CL and Byrnes $C A$. Efficacy and tolerability of finasteride in symptomatic benign prostatic hyperplasia: a primary care study. Primary Care Investigator Study Group. Clin Ther 1997; 19: 243-58.

26. McConnell JD, Bruskewitz R, Walsh P, Andriole G, Lieber $M$, Holtgrewe HL, Albertsen $P$, Roehrborn CG, Nickel JC, Wang DZ, Taylor AM and Waldstreicher J. The effect of finasteride on the risk of acute urinary retention and the need for surgical treatment among men with benign prostatic hyperplasia. Finasteride Long-Term Efficacy and Safety Study Group. N Engl J Med 1998; 338: 557-63.

27. Park T and Choi JY. Efficacy and safety of dutasteride for the treatment of symptomatic benign prostatic hyperplasia (BPH): a systematic review and metaanalysis. World J Urol 2014; 32: 1093-105. 